\title{
Study on the Mechanical Properties and Damage Constitutive Model of Hybrid Fibre- Reinforced EPS Lightweight Aggregate Concrete
}

\author{
Huang WEI, Miao XIN-WEI*, Sun YU-JIAO, Reng SHANSHAN
}

\begin{abstract}
The mechanical properties of hybrid fibre (polypropylene and wood)-reinforced expanded polystyrene (EPS) lightweight aggregate concrete was studied under various sand contents. Cubic and prismatic compression tests were carried out, through which the basic mechanical properties and stress-strain curves of the specimens were obtained. Moreover, the microstructures of the fibre-reinforced concrete with different sand proportions were analysed via scanning electron microscopy (SEM). The test results showed that as the sand proportion increased, the cubic compressive strength and prismatic compressive strength of the EPS lightweight aggregate concrete increased. The optimal slump was obtained when the sand ratio was $25 \%$, after which the slump declined. The EPS lightweight aggregate concrete exhibited obvious elastoplastic behaviour during compression, and the corresponding stress-strain curve could be divided into four stages: the elastic stage, strengthening stage, softening stage and collapse platform stage. Moreover, based on the test results and the damage theory and considering the coupling relationship between plasticity and damage, a damage constitutive model was proposed for hybrid fibre-reinforced EPS lightweight aggregate concrete under uniaxial compression.
\end{abstract}

Keywords: damage constitutive model; EPS lightweight aggregate concrete; hybrid fibre; polypropylene fibre; wood fibre

\section{INTRODUCTION}

Hybrid fibre-reinforced concrete is a kind of composite material that contains two or more kinds of fibres in the matrix $[1,2]$. Adding fibres to concrete can greatly reduce shrinkage and cracking, increase toughness and tensile mechanical properties, and effectively improve plastic shrinkage, permeability, and frost resistance. In particular, the addition of fibres can significantly improve the performance of concrete under impact loads, fatigue loads and other dynamic loads [3-5].

Expanded polystyrene (EPS) is an environmentally friendly material commonly used in lightweight aggregate concrete that can significantly improve the thermal insulation and reduce the weight of concrete structures. Studies have shown that the mechanical properties of EPS concrete are related to the EPS particle size and distribution [6-9]. Moreover, increasing the volume of EPS will lead to a significant reduction in the flexural strength and compressive strength of concrete [10-12]. EPS can effectively improve the toughness and deformability of concrete, whereas the effect of EPS on concrete compressive strength is not obvious; thus, the EPS content should not be excessively large [13-14]. Furthermore, the incorporation of EPS has a substantial influence on the constitutive relationship of concrete. Based on axial compression tests, the stress-strain relationship of EPS concrete was studied and a constitutive model was proposed; the results from this model were in good agreement with the test results $[15,16]$. A proper mix proportion can significantly improve the comprehensive performance of EPS lightweight aggregate concrete and reduce the adverse effects of EPS on the mechanical properties of concrete. A comprehensive analysis of the mix proportion of EPS lightweight aggregate concrete and the corresponding mechanical properties was carried out in previous studies [17, 18].

An effective method to improve the mechanical properties of EPS lightweight aggregate concrete is the incorporation of hybrid fibres (high-strength fibres and polypropylene fibres) $[19,20]$. At present, steel fibres are the most commonly selected high-strength fibre. Hosein
[21] studied the effect of silica fume on the mechanical properties of hybrid fibre (steel and polypropylene)reinforced lightweight concrete, wherein they found that the addition of steel fibres can effectively improve the mechanical properties of EPS lightweight aggregate concrete. Libre et al. [22] studied the improvement in the ductility of pumice lightweight aggregate concrete from the hybrid reinforcement of steel and polypropylene fibres. Their results showed that the hybrid fibre reinforcement was beneficial for improving the workability, reducing the bulk density and improving the mechanical behaviour concrete. However, few studies have been reported on improving the mechanical properties of EPS lightweight aggregate concrete reinforced with wood fibres. In this paper, the mechanics of hybrid fibre (polypropylene fibrewood fibre)-reinforced EPS lightweight aggregate concrete were studied under different sand proportions. Combined with damage theory and considering the coupling relationship between plasticity and damage, the damage constitutive model of hybrid fibre-reinforced EPS lightweight aggregate concrete under uniaxial compression was proposed.

\section{TESTING CONDITIONS \\ 2.1 Test Material}

The constituents of the hybrid fibre-reinforced EPS lightweight aggregate concrete used in this experiment are as follows: 42.5R ordinary Portland cement, which was produced in the Shanxi Qinling cement factory (the basic physical properties of cement is shown in Tab. 1, and the chemical composition of the cement is shown in Tab. 2). River sand (fineness modulus of 2.14). Expanded Polystyrene (particle size of 3 - $7 \mathrm{~mm}$ and bulk density of $12 \mathrm{~kg} / \mathrm{m}^{3}$ ). The chemical composition of the silica fume is shown in Tab. 2. Emulsion powder (ethylene-vinyl acetate, EVA). Water-retaining agent (hydroxypropylmethyl cellulose ether, 200000 consistency). Hybrid fibres and tap water.The polypropylene fibres (produced by the Xi'an BossettFiber Co., Ltd.) had a specific gravity of 0.88 , a tensile strength of $550-760 \mathrm{MPa}$, and a diameter of approximately $100 \mu \mathrm{m}$. The wood fibres (produced by the 
Tianjin Baihui Chemical Co., Ltd.) were composed of industrial eucalyptus. Equal amounts of the two fibre types were used in the samples. The length of the polypropylene fibres was $10 \mathrm{~mm}$, whereas that of the wood fibres was 0.5 - $3 \mathrm{~mm}$. The physical mechanical properties of the fibres are shown in Tab. 2. The water-reducing agent, UNF-MA naphthalene high-efficiency water reducer, was produced by the Xi'an Aerospace Group Co., Ltd.; the water reduction rate was $30 \%$.

Table 1 Physical mechanical properties of cement

\begin{tabular}{|c|c|c|c|c|c|c|c|c|c|}
\hline \multirow{2}{*}{$\begin{array}{c}\text { Water requirement for } \\
\text { normal consistency }\end{array}$} & \multirow{2}{*}{ Stability } & \multirow{2}{*}{ Chloride / \% } & \multicolumn{2}{|c|}{ Setting time /min } & \multicolumn{2}{|c|}{ Flexural strength / MPa } & Compressive strength / MPa \\
\cline { 4 - 8 } & & & Initial setting & Final setting & $3 \mathrm{~d}$ & $28 \mathrm{~d}$ & $3 \mathrm{~d}$ & $28 \mathrm{~d}$ \\
\hline $25.1 \%$ & Qualified & 0.012 & 203 & 230 & 5.9 & 7.7 & 27.4 & 45 & \\
\hline
\end{tabular}

Table 2 Chemical composition of the cement and silica fume

\begin{tabular}{|c|c|c|c|c|c|c|c|c|}
\hline & \multicolumn{8}{|c|}{ Chemical composition / \% } \\
\hline & $\mathrm{CaO}$ & $\mathrm{Al}_{2} \mathrm{O}_{3}$ & $\mathrm{SiO}_{2}$ & $\mathrm{TiO}_{2}$ & $\mathrm{Fe}_{2} \mathrm{O}_{3}$ & $\mathrm{MgO}$ & $\mathrm{SiO}_{3}$ & Loss of ignition \\
\hline Cement & 58.70 & 5.45 & 22.25 & 0.75 & 3.76 & 2.63 & 2.67 & 1.60 \\
\hline Silica fume & 0.54 & 0.51 & 94.80 & - & 1.12 & 0.75 & - & 1.90 \\
\hline
\end{tabular}

Table 3 Physical mechanical properties of the wood fibres and polypropylene fibres [28]

\begin{tabular}{|c|c|c|c|c|c|}
\hline Fibre type & Length $/ \mathrm{mm}$ & Density $/ \mathrm{gcm}^{-3}$ & Tensile strength / MPa & Elastic modulus / GPa & Elongation at break / \% \\
\hline Polypropylene fiber & $9-10$ & 0.91 & $400-700$ & $4-9$ & $7-9$ \\
\hline Wood & $0.5-3$ & 0.80 & $30-50$ & $2-3$ & $2-4$ \\
\hline
\end{tabular}

\subsection{Proportion Design}

The fibre-reinforced EPS lightweight aggregate concrete was tested under the variation of a single parameter: the sand proportion. In this study, the sand proportion was increased from $0 \%$ to $30 \%$ in $5 \%$ increments. A total of 7 sets of test samples were designed, and the same ratio was met according to the specifications. There are three test blocks in each group: a cubic compression testing block with dimensions of $100 \mathrm{~mm} \times$
$100 \mathrm{~mm} \times 100 \mathrm{~mm}$, a prismatic compression testing block with dimensions of $100 \mathrm{~mm} \times 100 \mathrm{~mm} \times 300 \mathrm{~mm}$ and a prismatic flexural strength testing block with dimensions of $150 \mathrm{~mm} \times 150 \mathrm{~mm} \times 550 \mathrm{~mm}[23,24]$. All of these blocks are used in the measurement of axial compressive strength and elastic modulus and to record the corresponding stress-strain curve. Each test block is mechanically vibrated and compacted, and the corresponding mixing ratios are shown in Tab. 4.

\begin{tabular}{|c|c|c|c|c|c|c|c|c|c|}
\hline Sample & EPS / L & $\begin{array}{c}\text { Emulsion } \\
\text { powder / kg }\end{array}$ & $\begin{array}{l}\text { Cellulose } \\
\text { ether } / \mathrm{kg}\end{array}$ & $\begin{array}{l}\text { Polypropylene fibres } \\
\text { (wood fibres) } / \mathrm{kg}\end{array}$ & $\begin{array}{c}\text { Silica fume / } \\
\mathrm{kg}\end{array}$ & $\begin{array}{c}\text { Water-proofing } \\
\text { agent } / \mathrm{kg}\end{array}$ & $\begin{array}{c}\text { Naphthalene } \\
\text { superplasticizer / } \\
\mathrm{kg}\end{array}$ & $\begin{array}{l}\text { Cement } \\
\text { / kg }\end{array}$ & $\begin{array}{c}\text { Sand } \\
\text { proportion }\end{array}$ \\
\hline BWS-1 & 1144 & 16.44 & 0.75 & 1.144 & 41 & 0.858 & 1.5 & 286 & $0 \%$ \\
\hline BWS-2 & 1144 & 16.44 & 0.75 & 1.144 & 41 & 0.858 & 1.5 & 286 & $5 \%$ \\
\hline BWS-3 & 1144 & 16.44 & 0.75 & 1.144 & 41 & 0.858 & 1.5 & 286 & $10 \%$ \\
\hline BWS-4 & 1144 & 16.44 & 0.75 & 1.144 & 41 & 0.858 & 1.5 & 286 & $15 \%$ \\
\hline BWS-5 & 1144 & 16.44 & 0.75 & 1.144 & 41 & 0.858 & 1.5 & 286 & $20 \%$ \\
\hline BWS-6 & 1144 & 16.44 & 0.75 & 1.144 & 41 & 0.858 & 1.5 & 286 & $25 \%$ \\
\hline BWS-7 & 1144 & 16.44 & 0.75 & 1.144 & 41 & 0.858 & 1.5 & 286 & $30 \%$ \\
\hline
\end{tabular}

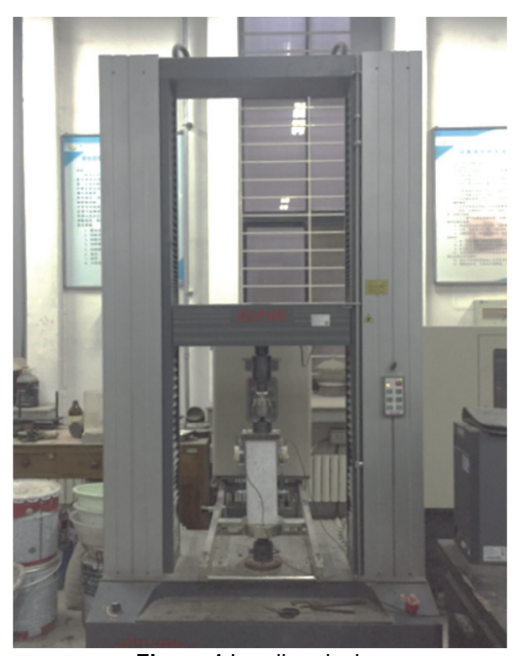

Figure 1 Loading device

\subsection{Loading Device and Test Method}

A DNS300 electronic universal testing machine was used for the cubic compressive strength test under the displacement-controlled loading mode. The loading speed was $1 \mathrm{~mm} / \mathrm{min}$, and the relative error of the indicated value was less than or equal to $\pm 1 \%$. A CMT5101 mechanical universal testing machine was used in the axial compressive strength test under the displacementcontrolled loading mode, as shown in Fig. 1. The loading speed was $0.2 \mathrm{~mm} / \mathrm{min}$ [23], and the whole loaddisplacement process of the test piece was obtained by a data acquisition device.

\section{TEST RESULTS AND ANALYSIS 3.1 Experimental Phenomena}

At the beginning of loading, some small cracks appeared at the compression edge of the upper and lower parts of the cubic test block. As the load increased, small debris fell off from the fluctuating margin, and $45^{\circ}$ inclined cracks appeared along the sample; these cracks propagated as the load increased, gradually extending to the upper and lower corners of the test block. As the load continued to increase, the EPS particles at the crack began to rupture, the original crack widened and deepened, and debris shed 
from the test block. The final failure of the sample occurred when the $45^{\circ}$ crack ran through the entire test block, as shown in Fig. 2a. In the whole compression process, the sample integrity was relatively intact; eventually, the sample showed plastic damage.The axial compression failure demonstrated that the sample exhibited good plastic deformation ability. In the initial stage of loading, some fine cracks appeared at the upper and lower pressurebearing edges. As the load increased, the crack gradually developed obliquely. When the load was close to the peak, vertical cracks appeared in the middle part of the test block. As the load continued to increase, the oblique cracks at the upper and lower ends gradually connected, and the vertical cracks deepened and widened. In the final failure state, the cracks were bulged, debris was falling off, and the specimen was greatly deformed; however, the sample still maintained good integrity. The damage of the prismatic specimens is shown in Fig. 2a.
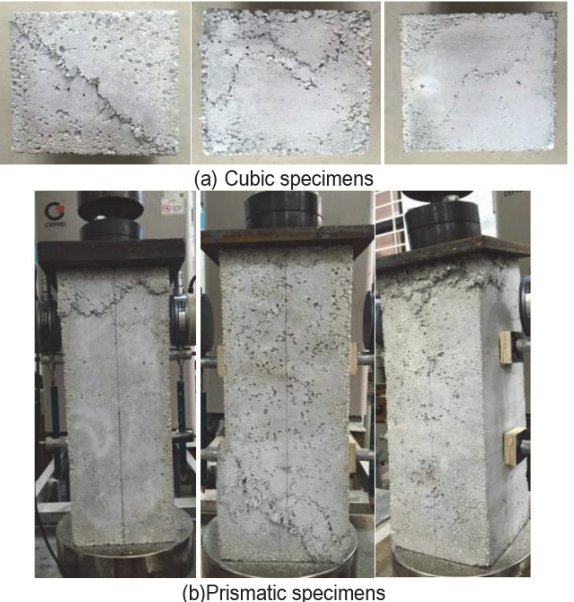

Figure 2 Compression failure mode of specimens: (a) Cubic specimens, (b) Prismatic specimens

Table 5 Experimental results of EPS lightweight aggregate concrete under different sand proportions

\begin{tabular}{|c|c|c|c|c|c|c|}
\hline Sample & $\begin{array}{c}\text { Compression } \\
\text { strength / MPa }\end{array}$ & $\begin{array}{c}\text { Axial compression } \\
\text { strength / MPa }\end{array}$ & $\begin{array}{c}\text { Thermal conductivity / } \\
\mathrm{Wm}^{-1} \mathrm{~K}^{-1}\end{array}$ & Flexural strength / MPa & $\begin{array}{c}\text { Slump / mm } \\
\text { Initial elastic modulus / } \\
\mathrm{MPa}\end{array}$ \\
\hline BWS-1 & 1.47 & 1.12 & 0.109 & 0.63 & 62.5 \\
\hline BWS-2 & 1.54 & 1.24 & 0.137 & 0.68 & 65.5 \\
\hline BWS-4 & 1.55 & 1.29 & 0.128 & 0.71 & 69.0 \\
\hline BWS-5 & 1.82 & 1.33 & 0.135 & 0.73 & 76.5 \\
\hline BWS-6 & 1.93 & 1.35 & 0.148 & 0.76 & 201 \\
\hline BWS-7 & 1.99 & 1.39 & 0.168 & 0.77 & 212 \\
\hline
\end{tabular}

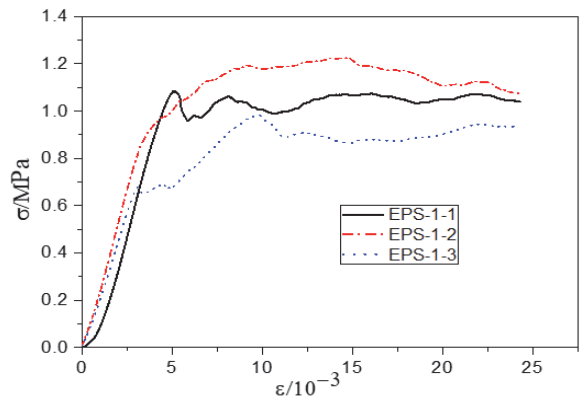

(a) EPS-1

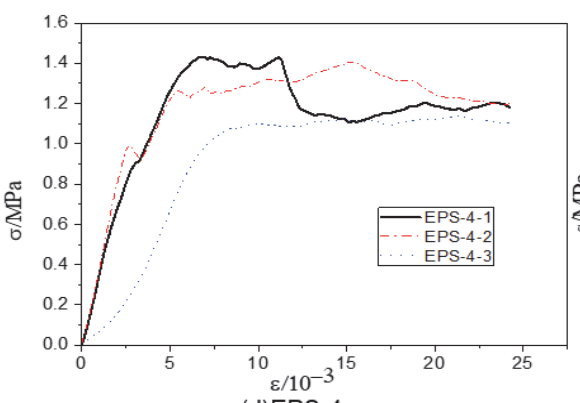

(d)EPS-4

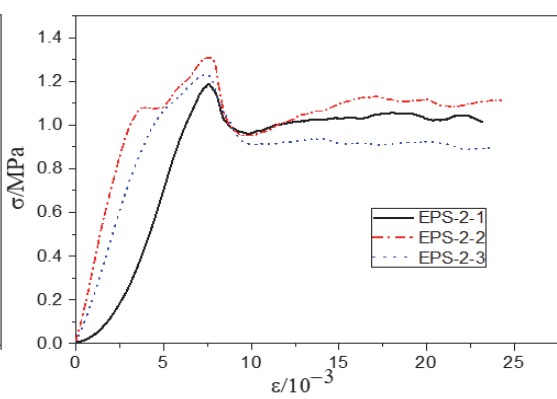

(b) EPS-2

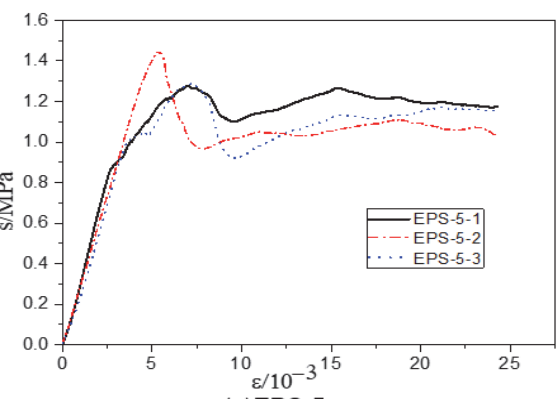

(e)EPS-5

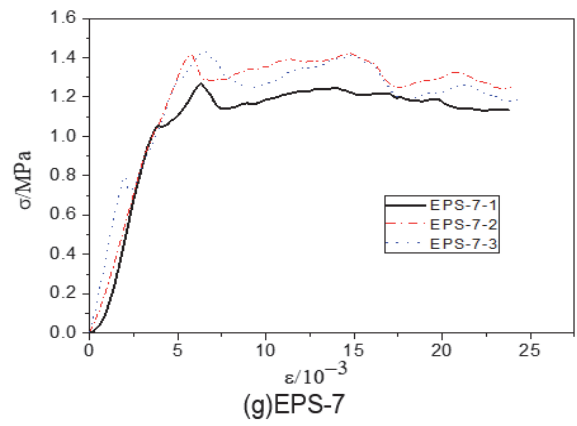

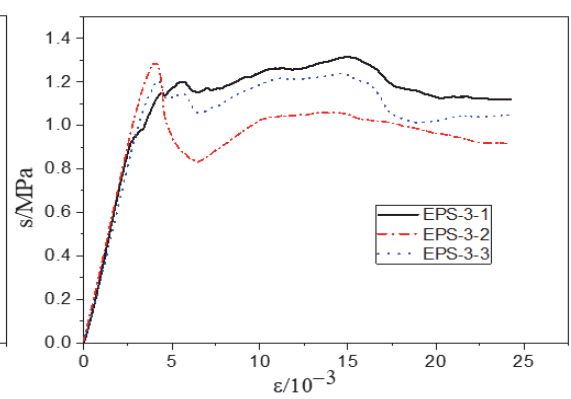

(c)EPS-3

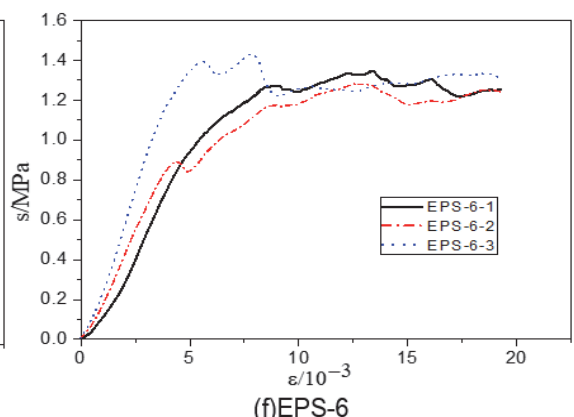

(f)EPS-6

Figure 3 Stress-strain curves of the prismatic specimens: (a) EPS-1, (b) EPS-2, (c) EPS-3, (d) EPS-4, (e) EPS-5, (f) EPS-6, (g) EPS-7 


\subsection{Mechanical Performance Index}

Tab. 5 shows that as the sand proportion increases, the cubic and axial compressive strength of EPS lightweight aggregate concrete tends to gradually increase. When the sand proportion is $30 \%$, the cubic and axial compressive strength of concrete reached a maximum. When the sand proportion is $25 \%$, the concrete has the largest slump and the best workability. Under the same conditions, when the sand proportion is small, the coarse aggregate has a large specific gravity, and the mortar layer between the coarse aggregates is thin, which cannot ensure an effective joint between the coarse aggregates and may cause slurry flowing and drying cracking, resulting in lower concrete strength. As the sand proportion increases, the specific surface area of the aggregate increases, and the amount of slurry wrapping the surface of the coarse aggregate increases, which ensures the joint strength between the aggregates and avoids the loss of slurry; thus, the workability of concrete increases. However, when the sand proportion exceeds a certain limit, the relative amount of cement slurry is reduced, and the lubricating effect is greatly reduced; as a result, the workability is deteriorated and the strength is not increased much.

\subsection{Full Stress-Strain Curve}

The rising section of the stress-strain curve of hybrid fibre-reinforced EPS lightweight aggregate concrete has a number of undulating and falling sections, in which the force first linearly increases to a peak point, drops, violently fluctuates, and then rises again to a point lower than the starting peak point. This process often has to go through several falling stages before stabilizing. This unique full-curve shape is determined by the properties of the EPS particles, which are porous solid materials. The compression of EPS is actually the process of the pore wall continuously yielding, then collapsing and compacting. The long collapse platform on the stress-strain curve indicates that the EPS lightweight aggregate concrete has a strong seismic capacity. The entire stress-strain curve can be summarized as an elastic phase, a strengthening phase, a softening phase, and a collapse platform phase. However, in the stress-strain curves of some hybrid fibre-reinforced EPS lightweight aggregate concrete samples, a long platform segment appears immediately after the stress reaches the peak. This phenomenon occurs because the EPS particles in this test have a large volume and the entire block gel material is too compact to form a strong and complete brittle network. Therefore, when some test blocks are under pressure, the operation of the test equipment is slightly improper, and the initial impact load is too high, which will cause the pore walls in the EPS lightweight aggregate concrete to collapse. After the pore walls collapse, the sample will immediately exhibit brittle behaviour after the stress peak is reached.

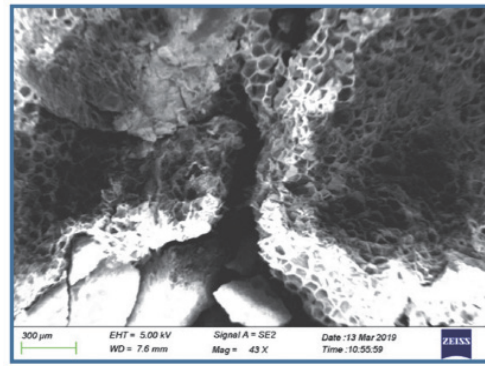

(a) Micromorphology
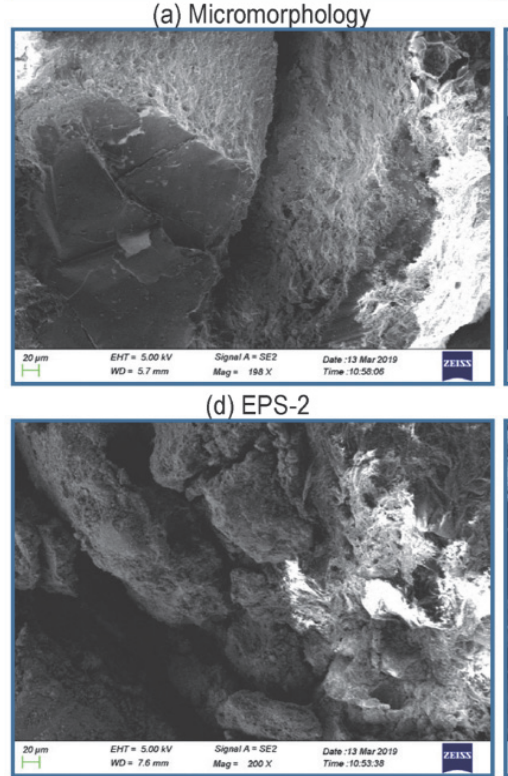

(g) EPS-5

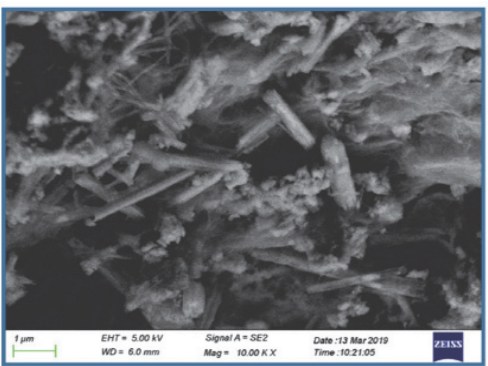

(b) Fibre morphology
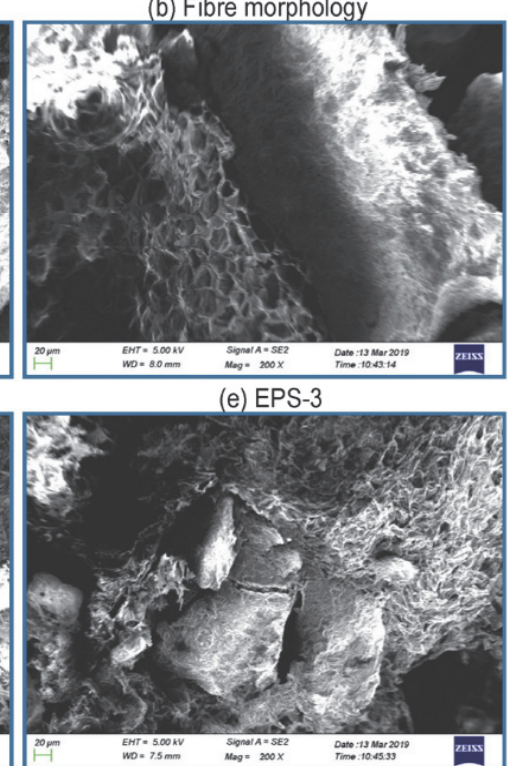

(h) EPS-6

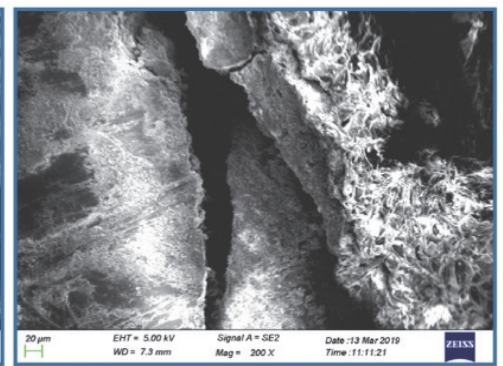

(c) EPS-1
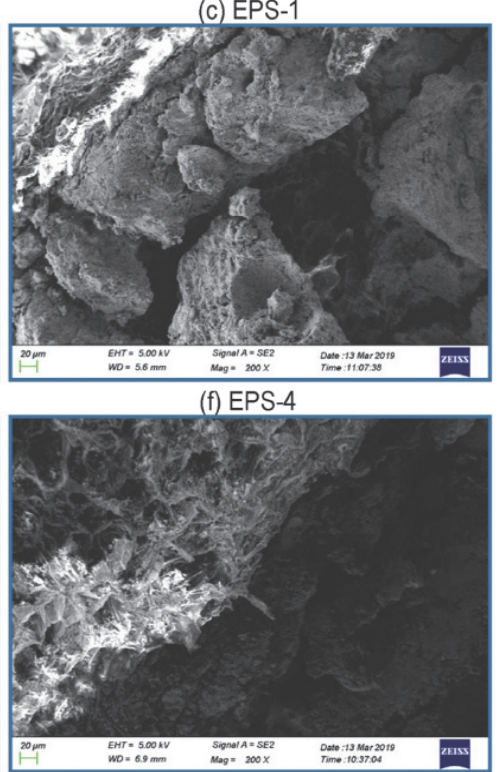

(i) EPS-7

Figure 4 SEM images of fibre-reinforced EPS lightweight aggregate concrete:(a) micromorphology, (b) fibre morphology, (c) EPS-1, (d) EPS-2, (e) EPS-3, (f) EPS-4, (g) EPS-5, (h) EPS-6, and (i) EPS-7 


\subsection{Microstructure}

The micromorphology of fibre-reinforced concrete with different sand proportions was analysed via scanning electron microscopy (SEM). Fig. 4a shows that the micromorphology of EPS is a honeycomb pore structure, and the structure itself does not have load-bearing capacity. The interface of EPS and slurry is mainly an enrichment zone of calcium silicate hydrate $(\mathrm{CSH})$, which has a loose network structure. Fig. $4 \mathrm{~b}$ shows that the fibres are interlaced inside the EPS concrete; the fibres can stably penetrate into the matrix, forming a complex threedimensional reinforced network, connecting the transition zone of the EPS and slurry, and enhancing the crack resistance of the interface. Moreover, some fibres pass through some small cracks, which provides a good pullout effect and slightly retards the development of cracks in the transition zone. Fig. $4 \mathrm{c}$ to Fig. $4 \mathrm{i}$ shows the micromorphology of the junction of hybrid fibrereinforced EPS lightweight aggregate concrete with different sand contents. As the sand proportion increases, the cracks at the EPS/concrete interface and the matrix surface gradually become finer and smaller. When the sand proportion is small (as shown in Fig. 4c), there are large drying cracks on the concrete surface. As the sand proportion increases, the total surface area of the aggregate increases, improving the workability of concrete under the same mix ratio. When the sand proportion reaches a certain level, the micromorphology of the concrete tends to become dense (as shown in Fig. 4i). The analysis results show that the bond between the fibre and the matrix is good in a certain dosage range, which can effectively inhibit crack growth. Moreover, a proper sand content can reduce the proportion of harmful pores in the concrete and improve the pore structure.

\section{ELASTOPLASTIC DAMAGE CONSTITUTIVE MODEL}

According to the damage mechanism of EPS lightweight aggregate concrete in the process of uniaxial compression failure, considering the coupling relationship between plasticity and damage [25] and the traditional framework of continuous damage mechanics and plastic mechanics, the development of unrecoverable deformation was studied. Through this study, an elastoplastic damage constitutive model was established for hybrid fibrereinforced EPS lightweight aggregate concrete.

\subsection{Elastoplastic Damage Constitutive Model Establishment}

Herein, it is assumed that the material damage is isotropic [26], and a damage variable is introduced as the internal variable in the constitutive relation through the macroscopic mechanical method. The evolution equation, which can describe the variation in the damage variable, and the physical constitutive equations of the damaged material are established [27]. Effective stress is defined in continuum damage mechanics as the damage variable to reflect the relative relationship between the geometry of the damaged and undamaged material. According to Lemaitre's "equivalent strain" hypothesis [28], the strain response of a damaged material under nominal stress is equivalent to the strain response of an undamaged material under effective stress.

In the small deformation elastoplastic theory, the constitutive equation of uniaxial compression damage is represented by equivalent plastic strain:

$\sigma_{\mathrm{c}}=E_{0}\left(1-D_{\mathrm{c}}\right)\left(\varepsilon-\tilde{\varepsilon}^{p l}\right)$

Combined with the characteristics of the stress-strain test curve of hybrid fibre-reinforced EPS lightweight aggregate concrete under uniaxial compression, the classical elastic damage evolution was compared and analysed, and the two-fold damage variable evolution model [29] was used, as shown in Fig. 5. The damage evolution equation is expressed in Eq. (2):

$D= \begin{cases}0 & \varepsilon \leq \varepsilon_{f} \\ 1-\frac{\eta-\lambda}{\eta-1} \cdot \frac{\varepsilon_{f}}{\varepsilon}+\frac{1-\lambda}{\eta-1} & \varepsilon_{f} \leq \varepsilon \leq \varepsilon_{r} \\ 1-\lambda \frac{\varepsilon_{f}}{\varepsilon} & \varepsilon_{r} \leq \varepsilon \leq \varepsilon_{u} \\ 1 & \varepsilon>\varepsilon_{u}\end{cases}$

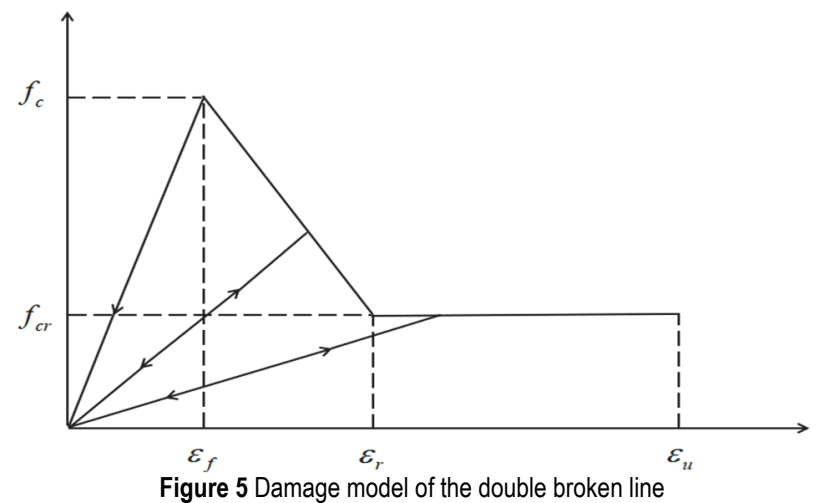

After exceeding the ultimate stress, the stress-strain curve enters the softening phase. The hardening data are given by the inelastic strain $\tilde{\varepsilon}^{i n}$, whose value is the difference between the total compressive strain $\varepsilon_{\mathrm{c}}$ and the compressive elastic strain $\varepsilon_{0 \mathrm{c}}^{e l}$ before the damage begins to accumulate, as shown in Fig. 6. According to the compression damage curve, the inelastic strain $\tilde{\varepsilon}^{i n}$ and the plastic strain $\tilde{\varepsilon}^{p l}$ have the following conversion relationship:

$\tilde{\varepsilon}^{p l}=\tilde{\varepsilon}^{i n}-\left(\varepsilon^{e l}-\varepsilon_{0 \mathrm{c}}^{e l}\right)$

where:

$\varepsilon^{e l}=\frac{\sigma_{\mathrm{c}}}{E_{0}(1-D)}$

According to Eq. (3) and Eq. (4), we can obtain the following expression:

$\tilde{\varepsilon}^{p l}=\tilde{\varepsilon}^{i n}-\frac{D_{\mathrm{c}} \sigma_{\mathrm{c}}}{\left(1-D_{\mathrm{c}}\right) E_{0}}$ 
If there is no damage, i.e., $D_{\mathrm{c}}=0$, then $\tilde{\varepsilon}_{\mathrm{c}}^{p l}=\tilde{\varepsilon}_{\mathrm{c}}^{p l}$.

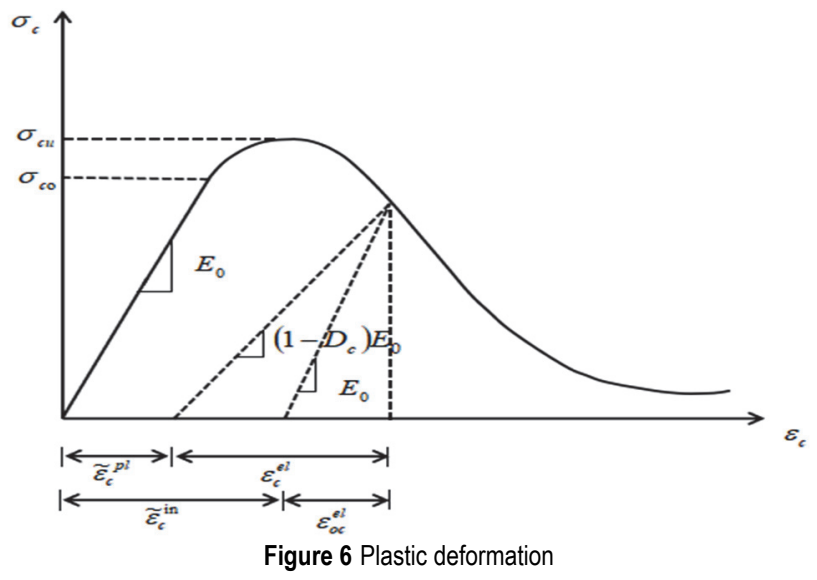

\subsection{Uniaxial Compression Damage Constitutive Model 4.2.1 Mechanical Characteristics of the Uniaxial Compression Process}

The test results showed that the failure process of hybrid fibre-reinforced EPS lightweight aggregate concrete can be roughly divided into two stages of elasticity and plasticity under uniaxial compression. Before the load reached $80 \%$ of the peak load, the stress and strain increased approximately proportionally. In this stage, there were no obvious cracks on the surface of the test piece, and the cracks inside the concrete were in a relatively stable state. When the load increased from the proportional limit to the critical load (approximately $90 \%$ of the peak load), the strain gradually increased and accelerated, exceeding the rate of stress increase; hence, the slope of the stressstrain curve decreased. At this point, the cracks in the EPS lightweight aggregate concrete were in a gradually increasing phase, during which the cracks gradually connected as they expanded. When the ultimate load was reached, the deformation rate continued to increase, the interfacial cracks continued to develop, and visible cracks appeared on the surface of the EPS lightweight aggregate concrete. The stress began to decrease with increasing strain, and the decreasing amplitude gradually decreased, finally approaching the horizontal state, which was called the "residual strength stage".

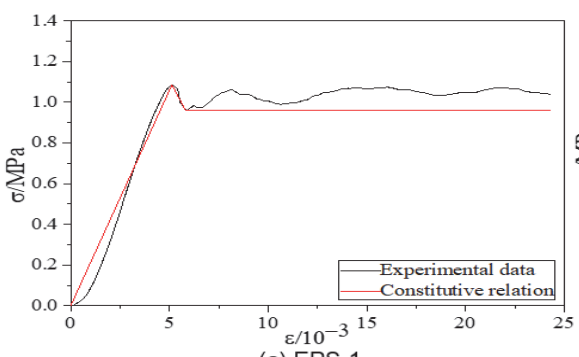

(a) EPS-1

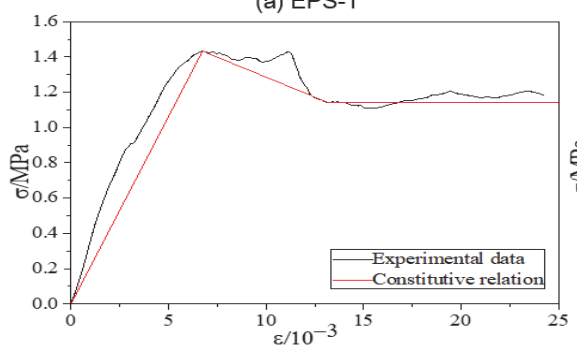

(d) EPS-4

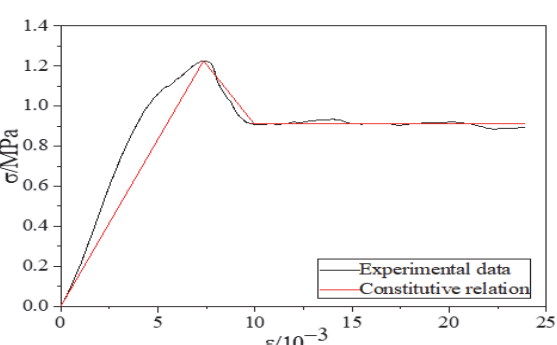

(b) EPS-2

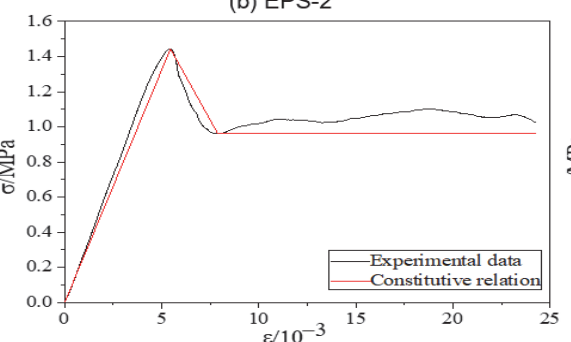

(e) EPS-5

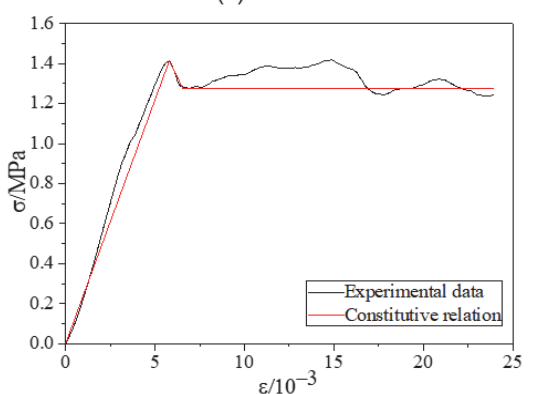

(g) EPS-7

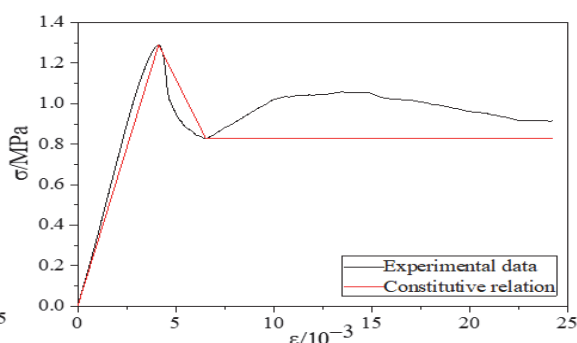

(c) EPS-3

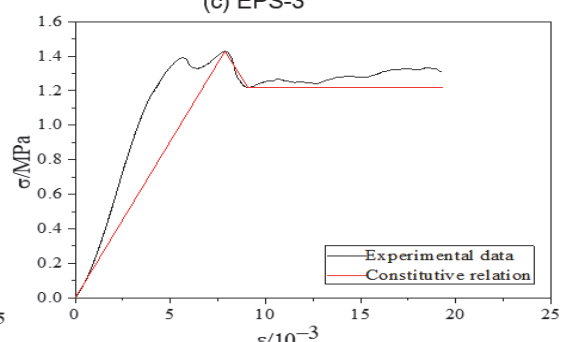

(f) EPS $^{E / 1} 10^{-3}$

Figure 7 Comparison of uniaxial compression test curves and constitutive relations of specimens

\subsubsection{Constitutive Model of Uniaxial Compression Damage}

According to the above mechanical characteristics of the uniaxial compression process, the compression damage constitutive model of hybrid fibre-reinforced EPS lightweight aggregate concrete can be divided into the following three stages: the elastic phase, the plastic phase, and the residual strength phase.
In the elastic phase, the concrete exhibits no plastic deformation and has no internal damage. The constitutive relationship is as follows:

$$
\left\{\begin{array}{l}
D_{\mathrm{c}}=0 \\
\tilde{\varepsilon}_{\mathrm{c}}^{p l}=0 \\
\sigma_{\mathrm{c}}=E_{0} \varepsilon_{\mathrm{c}}
\end{array} \quad \varepsilon_{\mathrm{c}} \leq \varepsilon_{\mathrm{f}}\right.
$$


In the plastic phase, when the strain exceeds the elastic limit strain $\varepsilon_{\mathrm{f}}$, microcracks appear inside the concrete and plastic deformation occurs; thus, the damage initiates and starts to accumulate. The constitutive relationship is as follows:

$$
\left\{\begin{array}{l}
D_{\mathrm{c}}=1-\frac{\eta-\lambda}{\eta-1} \frac{\varepsilon_{\mathrm{f}}}{\varepsilon_{\mathrm{c}}}+\frac{1-\lambda}{\eta-1} \\
\tilde{\varepsilon}_{\mathrm{c}}^{p l}=\tilde{\varepsilon}_{\mathrm{c}}^{i n}-\frac{D_{\mathrm{c}}}{1-D_{\mathrm{c}}} \frac{\sigma_{\mathrm{c}}}{E_{0}} \quad \varepsilon_{\mathrm{f}}<\varepsilon_{\mathrm{c}}<\varepsilon_{\mathrm{r}} \\
\sigma_{\mathrm{c}}=\left(1-D_{\mathrm{c}}\right) E_{0}\left(\varepsilon_{\mathrm{c}}-\varepsilon_{\mathrm{c}}^{p l}\right)
\end{array}\right.
$$

In the residual strength phase, the concrete has macroscopic cracks but still maintains a certain strength. The constitutive relationship is as follows:

$$
\left\{\begin{array}{l}
D_{\mathrm{c}}=1-\lambda \frac{\varepsilon_{\mathrm{f}}}{\varepsilon_{\mathrm{c}}} \varepsilon_{\mathrm{f}}<\varepsilon_{\mathrm{c}} \\
\sigma_{\mathrm{c}}=\lambda E_{0} \varepsilon_{\mathrm{f}}
\end{array}\right.
$$

\subsection{Comparative Analysis of the Test Stress-Strain Curve and the Theoretical Curve}

To verify the constitutive model of hybrid fibrereinforced EPS lightweight aggregate concrete proposed in this paper, the experimental and theoretical stress-strain curves were compared, as shown in Fig. 7. The damage constitutive model of the hybrid fibre-reinforced EPS lightweight aggregate concrete proposed in this paper agrees well with the experimental results, accurately reflecting the characteristics of the uniaxial compressive stress-strain curve. The initial elastic modulus $E_{0}$, peak stress $f_{\mathrm{c}}$, peak strain $\varepsilon_{\mathrm{f}}$ and cracking strain $\varepsilon_{\mathrm{r}}$ of each group

\begin{tabular}{|c|c|c|c|c|}
\hline Sample & Initial elastic modulus $E_{0} / \mathrm{MPa}$ & Peak stress $f_{\mathrm{c}} / \mathrm{MPa}$ & Peak strain $\varepsilon_{\mathrm{f}}$ & Cracking strain $\varepsilon_{\mathrm{r}}$ \\
\hline BWS-1-1 & 192 & 1.08573 & 0.00513 & 0.00582 \\
\hline BWS-2-1 & 201 & 1.22622 & 0.00735 & 0.00996 \\
\hline BWS-3-2 & 212 & 1.28943 & 0.00413 & 0.00653 \\
\hline BWS-4-1 & 233 & 1.43285 & 0.00674 & 0.01318 \\
\hline BWS-5-2 & 246 & 1.44301 & 0.00545 & 0.00788 \\
\hline BWS-6-3 & 249 & 1.42788 & 0.00786 & 0.00908 \\
\hline BWS-7-2 & 278 & 1.41292 & 0.00579 & 0.00656 \\
\hline
\end{tabular}
obtained in the test are shown in Tab. 6.

\section{CONCLUSION}

In this paper, the cubic compressive strength, axial compressive strength, slump and stress-strain curves of hybrid fibre-reinforced EPS lightweight aggregate concrete were studied under different sand proportions. The influence of changing parameters on the mechanical performance index was discussed. Based on the full stressstrain curves and test results of the concrete, the damage theory, and the coupling relationship between plastic and damage, a constitutive model of uniaxial compression damage was proposed for fibre-reinforced EPS lightweight aggregate concrete. The following conclusions were obtained from this study:

1) As the sand content increased and the content of other materials remained unchanged, the mechanical strength of hybrid fibre-reinforced EPS lightweight aggregate concrete increased. The maximum cubic compressive strength and axial compressive strength were obtained when the sand proportion was $30 \%$, whereas the optimal slump was obtained when the sand ratio was $25 \%$.

2) In this test, hybrid fibre-reinforced EPS lightweight aggregate concrete had a low density, the EPS content was high, and the stress-strain curve was influenced by the mechanical characteristics of the EPS particles. In the process of loading, the concrete exhibited obvious elastoplasticity and a good deformation capacity; thus, this concrete can absorb a large amount of energy and has a strong seismic resistance capacity under a certain load. The full stress-strain curve of EPS lightweight aggregate concrete can be divided into four stages: the elastic stage, strengthening stage, softening stage and collapse platform stage.

3) Based on continuous damage mechanics and plasticity theory, under the framework of the elastoplastic damage theory, and considering the coupling relationship between plasticity and damage, the damage evolution equation, the calculation formula of plastic deformation and the elastoplastic damage constitutive model of EPS lightweight aggregate concrete under uniaxial compression were proposed. The simulated results were compared with the experimental data to verify the validity of the model. The damage evolution behaviour of EPS lightweight aggregate concrete can be well described by the model. Therefore, this model can provide the theoretical basis for the structural design and analysis of composite walls with EPS lightweight aggregate concrete block infill.

\section{Acknowledgements}

This work was financially supported by the Natural Science Foundation of China (grant Nos. 51578446 and 51978566). The authors would like to express sincere thanks to Professor Huang.

\section{REFERENCES}

[1] Liang, N. H., Yang, P., Liu, X. R., \& Zhong, Y. (2018). A study on dynamic compressive mechanical properties of multi-size polypropylene fiber concrete under high strain rate. J. Materials Review, (2), 288-294.

[2] Banthia. N. \& Sheng, J. (1995). Micro-fiber Reinforced Cement Composites. II. Flexural Response and Fr. Canadian Journal of Civil Engineering, 22(22), 668-682. https://doi.org/10.1139//95-079

[3] Huo, J. F., Shen, X. D., Cui, Q., \& Li, J. S. (2007). Effect of Polypropylene Fiber on Mechanical Properties of Lightweight Aggregate Concrete. Bulletin of Silicate, 26(4), 700-704. https://doi.org/10.1016/S1001-6058(07)60030-4

[4] Zhan, B. G., Guo, J. L., \& Lin, X. S. (2009). Experimental study on properties of glass fiber reinforced foam concrete. Journal of Hefei University of Technology, 32(2), 226-229. 
[5] Wei, J. Y., Liu, H. W., \& Zhang, Y. (2017). Study on Impact Resistance of Steel-PVA Hybrid Fiber Concrete. Concrete, (12), 51-53.

[6] Liu, N. \& Chen, B. (2014). Experimental study of the influence of EPS particle size on the mechanical properties of EPS lightweight concrete. Construction and Building Materials, 68, 227-232. https://doi.org/10.1016/i.conbuildmat.2014.06.062

[7] Chung, S. Y., Elrahman, M., \& Stephan, D. (2018). Effects of expanded polystyrene (EPS) sizes and arrangements on the properties of lightweight concrete. Materials and Structures, 51(3), 57. https://doi.org/10.1617/s11527-018-1182-3

[8] Elsalah, J., Alsahli, Y., Akish, A., Saad, O. \& Hakemi, A. (2013). The influence of recycled expanded polystyrene (EPS) on concrete properties: Influence on flexural strength, water absorption and shrinkage. 3rd International Congress on Advances in Applied Physics and Materials, https://doi.org/10.1063/1.4849254

[9] Sayadi, A. A., Tapia, J. V., Neitzert, T. R., \& Clifton, G. (2016). Effects of expanded polystyrene (EPS) particles on fire resistance, thermal conductivity and compressive strength of foamed concrete. Construction and Building Materials, 112, 716-724. https://doi.org/10.1016/j.conbuildmat.2016.02.218

[10] Miled, K., Sab, K., \& Roy, R. L. (2007). Particle size effect on EPS lightweight concrete compressive strength: Experimental investigation and modelling. Mechanics of Materials, 39(3), 222-240. https://doi.org/10.1016/j.mechmat.2006.05.008

[11] Liu, N. \& Chen, B. (2014). Experimental study of the influence of EPS particle size on the mechanical properties of EPS lightweight concrete. Construction \& Building Materials, 68(4), 227-232. https://doi.org/10.1016/j.conbuildmat.2014.06.062

[12] Wang, Y., Long, W. S., \& Yin, Z. H. (2013). Experimental Research and Engineering Application of Polypropylene Fiber Concrete. Shanghai Construction Science \& Technology, (3), 57-60.

[13] Feldman, D., Zheng, Z., \& Synthetic. (2011). Fibres for Fibre Concrete Composites. Mrs Online Proceeding Library, 305. https://doi.org/10.1557/PROC-305-123

[14] Cui, C., Huang, Q., Li, D., \& Quan, C. (2016). Stress-strain relationship in axial compression for EPS concrete. Construction \& Building Materials, 105, 377-383. https://doi.org/10.1016/j.conbuildmat.2015.12.159

[15] Cheng, C. M., Su, D. G., Jiao, C. J., \& He, J. (2011). Experimental study on uniaxial compression of organic lightweight aggregate concrete. Journal of South China University of Technology (Natural Science Edition), 39(11), 114-119.

[16] Vakhshouri, B. \& Nejadi, S. (2017). Review on the mixture design and mechanical properties of the lightweight concrete containing expanded polystyrene beads. Australian Journal of Structural Engineering, 19(1), 1-23. https://doi.org/10.1080/13287982.2017.1353330

[17] Fan, Z. Y. (2009). Experimental study on properties of polypropylene fiber lightweight aggregate concrete. Hohhot: Inner Mongolia Agricultural University.

[18] Zhao, X. Y., Tian, W. Z., Zhou, M. J., \& Lei, M. O. (2009). Experimental study on mix ratio and performance of EPS lightweight aggregate concrete. Concrete, (2), 59-62.

[19] Peng, M., Huang, H. X., \& Liao, Q. H. (2012). Experimental study on basic mechanical properties of basalt fiber reinforced concrete. Concrete, (1), 74-75.

[20] Dias, D. P. \& Thaumaturgo, C. (2005). Fracture Toughness of Geopolymeric Concretes Reinforced With Basalt Fibers. Cement \& Concrete Composites, 27(1), 49-54. https://doi.org/10.1016/j.cemconcomp.2004.02.044
[21] Hosein, G. M. S. \& Ghorbani, S. S. Y. (2018). Experimental Study Effect of Silica Fume and Hybrid Fiber on Mechanical Properties Lightweight Concrete. Iranian Journal of Science and Technology. Transactions of Civil Engineering. https://doi.org/10.1007/s40996-018-0137-9

[22] Libre, N. A., Shekarchi, M., Mahoutian, M., \& Soroushian, P. (2011). Mechanical properties of hybrid fiberreinforcedhybridfiberreinf lightweight aggregate concrete made with natural pumice. Construction \& Building Materials, 25(5), 2458-2464. https://doi.org/10.1016/j.conbuildmat.2010.11.058

[23] GB/T50081-2002. (2002). Standard for test methods of mechanical properties of ordinary concrete. Architecture \& Building Press. Ministry of Housing and Urban-Rural Development of the People's Republic of China. Beijing, China.

[24] Duan, A. \& Qian, J. R. (2008). Experimental study on the full stress-strain curve of concrete in freeze-thaw environment. Concrete, (08), 19-22. https://doi.org/10.1088/1126-6708/2008/08/005

[25] Liu, Y. C. (2014). Study on EPS concrete test, constitutive model and energy saving evaluation. International earthquake dynamics, (3), 45-46.

[26] Yu, S. W. \& Feng, X. Q. (1997). Damage Mechanics. Tsinghua University Press. Beijing, China.

[27] Dong, K. L. (2015). Research on Basic Mechanical Performance of Fiber recycled brick aggregate concrete. Xi'an University Of Architecture And Technology.

[28] Sathe, P. D. \& Dawari, B. M. (2017). Elasto-plastic Damage Analysis Based on Strain-space Plasticity. Procedia Engineering, 173. https://doi.org/10.1016/j.proeng.2016.12.072

[29] Ma, H. F., Chen, H. Q., \& Li, B. Q. (2004). Meso-structure numerical simulation of concrete specimens. J. Journal of Hydraulic Engineering, (10), 27-35.

[30] Reng S. S. (2017). Experimental study on mechanical properties of fiber reinforced EPS insulation materials and seismic performance of composite wall with thermal insulation load-bearing. Xi'an University of Architecture and Technology. Xi'an, China.

\section{Contact information:}

Huang WEI, professor

Civil Engineering School, Xi'an University of Architecture and Technology, No.13 Yanta Road, Beilin District, Xi'an 710055, China

E-mail: qqhuangwei2005@126.com

Miao XIN-WEI, Lecturer

(Corresponding author)

College of Science, Xi'an University of Architecture and Technology,

No.13 Yanta Road, Beilin District, Xi'an 710055, China

E-mail: panzer.8002@163.com

Sun YU-JIAO, Master student

Civil Engineering School, Xi'an University of Architecture and Technology, No.13 Yanta Road, Beilin District, Xi'an 710055, China

E-mail:17862906200@163.com

Reng SHANSHAN, Master student

Civil Engineering School, Xi'an University of Architecture and Technology, No.13 Yanta Road, Beilin District, Xi'an 710055, China

E-mail: lbklbk2008@126.com 